University of Nebraska - Lincoln

DigitalCommons@University of Nebraska - Lincoln

2008

\title{
Myenteric neurons of the ileum that express somatostatin are a target of prion neuroinvasion in an alimentary model of sheep scrapie
}

\author{
David A. Schneider \\ U.S. Department of Agriculture \\ Huijun Yan \\ Washington State University \\ Lindsay M. Fry \\ Washington State University, lindsay.fry@usda.gov \\ Janet Alverson \\ U.S. Department of Agriculture \\ Stephen N. White \\ U.S. Department of Agriculture, Stephen.White@ARS.USDA.GOV
}

See next page for additional authors

Follow this and additional works at: https://digitalcommons.unl.edu/zoonoticspub

Part of the Veterinary Infectious Diseases Commons

Schneider, David A.; Yan, Huijun; Fry, Lindsay M.; Alverson, Janet; White, Stephen N.; and O'Rourke, Katherine I., "Myenteric neurons of the ileum that express somatostatin are a target of prion neuroinvasion in an alimentary model of sheep scrapie" (2008). Other Publications in Zoonotics and Wildlife Disease. 102.

https://digitalcommons.unl.edu/zoonoticspub/102

This Article is brought to you for free and open access by the Wildlife Disease and Zoonotics at DigitalCommons@University of Nebraska - Lincoln. It has been accepted for inclusion in Other Publications in Zoonotics and Wildlife Disease by an authorized administrator of DigitalCommons@University of Nebraska Lincoln. 


\section{Authors}

David A. Schneider, Huijun Yan, Lindsay M. Fry, Janet Alverson, Stephen N. White, and Katherine I. O'Rourke 


\title{
Myenteric neurons of the ileum that express somatostatin are a target of prion neuroinvasion in an alimentary model of sheep scrapie
}

\author{
David A. Schneider $\cdot$ Huijun Yan $\cdot$ Lindsay M. Fry $•$ \\ Janet Alverson • Stephen N. White $\cdot$ \\ Katherine I. O'Rourke
}

Received: 26 December 2007 / Revised: 21 March 2008 / Accepted: 22 March 2008 / Published online: 22 April 2008

(C) Springer-Verlag 2008

\begin{abstract}
Neuroinvasion of the enteric nervous system by prions is an important step in dissemination to the brain, yet very little is known about the basic process of enteric neuroinvasion. Using an alimentary model of neonatal disease transmission, neuroinvasion by scrapie prions in the ileum of lambs was detected by immunohistochemical staining for the disease-associated form of the prion protein, $\mathrm{PrP}^{\mathrm{Sc}}$. Odds ratios (OR) were determined for the frequency of $\mathrm{PrP}^{\mathrm{Sc}}$ staining within enteric somata categorized by plexus location (myenteric, submucosal) and neurochemical staining (PGP 9.5, neural nitric oxide synthase, somatostatin, substance $\mathrm{P}$, and vasoactive intestinal polypeptide). $\operatorname{PrP}^{\mathrm{Sc}}$ was observed in $4.48 \pm 4.26 \%$ of myenteric neurons and $2.57 \pm 1.82 \%$ of submucosal neurons in five lambs aged 208-226 days but not in a lamb aged 138 days. The relative frequency of $\operatorname{PrP}^{\mathrm{Sc}}$ within enteric somata was interdependent on plexus location and neurochemical type. Interestingly, $\mathrm{PrP}^{\mathrm{Sc}}$ was observed more frequently within myenteric neurons than in submucosal neurons (PGP 9.5; $\mathrm{OR}=1.72,95 \%$ confidence interval $=1.21-2.44$ ), and was observed within the myenteric plexus approximately $4 \times(2.16-6.94)$ more frequently in somatostatin neurons
\end{abstract}

\section{A. Schneider $(\bowtie) \cdot S$. N. White · K. I. O’Rourke}

Animal Disease Research Unit, Agricultural Research Service, US Department of Agriculture, 3003 ADBF, WSU, PO Box 646630, Pullman, WA 99164-6630, USA

e-mail: das@vetmed.wsu.edu

H. Yan · L. M. Fry

Department of Veterinary Microbiology and Pathology,

Washington State University, Pullman, WA 99164, USA

J. Alverson

Animal and Plant Health Inspection Service,

Veterinary Services, US Department of Agriculture,

Helena, MT 59601, USA than in the general neural population stained by PGP 9.5. Nerve fibers stained for somatostatin were present in the mucosa and near $\mathrm{PrP}^{\mathrm{Sc}}$ staining within Peyer's patches. The results suggest that somatostatin-expressing enteric neurons, with fiber projections near Peyer's patches, but with somata present in greatest proportion within the myenteric plexus, are an early target for neuroinvasion by scrapie prions and could serve an important role in neural dissemination.

Keywords Prion - Scrapie - Enteric nervous system · Somatostatin $\cdot$ Peyer's patches

\section{Introduction}

Prion diseases - or transmissible spongiform encephalopathies (TSEs) - are a group of slowly progressive, fatal neurologic diseases caused by unconventional agents called prions [39]. Although some debate persists regarding the exact nature of prions, disease is critically associated with the conversion of cellular host prion protein $\left(\mathrm{PrP}^{\mathrm{c}}\right)$ to TSEassociated isoforms $\left(\mathrm{PrP}^{\mathrm{TSE}}\right)$ [7, 38]. Natural prion disease occurs in humans (Creutzfeldt-Jakob disease and others) and in several types of animals significant to agriculture (scrapie of sheep and goats and bovine spongiform encephalopathy of domestic cattle) and to wildlife management (chronic wasting disease of deer and elk).

Disease transmission commonly occurs via the alimentary tract but specific knowledge about how prions disseminate from the gut to the brain is incomplete (see reviews by Mabbot and MacPherson [28] and by Beekes and McBride [5]). Neuroinvasion occurs in the periphery and results in dissemination to the brain via autonomic nerves; in particular, parasympathetic and sympathetic efferent nerves projecting to the gut are thought to be common pathways. 
However, the gut is most extensively innervated by a third division of the autonomic nervous system, the enteric nervous system (see reviews by Brookes and Costa [6], and Furness [15]). It is estimated in sheep that the small intestine alone contains more than 30 million myenteric and 50 million submucosal neurons, a total population that rivals that in the spinal cord [16].

The enteric nervous system is a functionally complete, ganglionated nerve network that is organized into a myenteric plexus and a submucosal plexus, out of which all layers of the gut wall are innervated. With some variation amongst species, there is a division of labor such that most neurons which control gut motility are located within the myenteric plexus, and most neurons which control mucosal blood flow and secretion are located within the submucosal plexus. Coordination is achieved through inter-plexus enteric projections, extrinsic autonomic projections, and viscerofugal projections from the enteric nervous system to prevertebral ganglia.

The enteric nervous system includes many different neuron classes, which have been classified not only by plexus location and region of the alimentary tract, but also by somato-dendritic morphology, electrophysiology, neurochemistry, fiber projection, and physiologic action on a target tissue. Major functional classes of enteric neuron include intrinsic primary afferent neurons and several types each of interneurons, smooth muscle motor neurons, secretomotor neurons, and vasomotor neurons. Though not fully characterized, even local gut immune function is modulated by the enteric nervous system, in part through peptidergic innervation of Peyer's patches [50]. The enteric nervous system is thus a complex neural system that is intimately associated with all layers of the gut, including the mucosal layer through which prions gain entry into the host, and Peyer's patches in which prion replication occurs early in disease progression.

Given that extrinsic autonomic nerves synapse with enteric neurons [15], that enteric neurons express $\operatorname{PrP}^{\mathrm{c}}$ [40] and innervate all layers of the gut, and that scrapie-associated prion protein $\left(\mathrm{PrP}^{\mathrm{Sc}}\right)$ is first detected in sheep within the enteric nervous system $[3,19,46]$, it is hypothesized that neuroinvasion of the enteric nervous system is important for the dissemination of scrapie prions to the brain via autonomic nerves.

Many observations suggest that neurons projecting into sites of prion replication (Peyer's patches) should be targets for invasion by prions [5, 28], but a more diverse group of neurons (with projections into the mucosa or around vessels) may be exposed immediately following uptake of prions from the gut lumen [25]. The purpose of this study was to identify enteric neural targets of scrapie prions early in disease progression in a natural disease model in lambs. The results demonstrate that following neonatal alimentary disease transmission, frequency of $\mathrm{PrP}^{\mathrm{Sc}}$ detection within ileal enteric neurons is disproportionately greater for myenteric neurons expressing the peptide transmitter, somatostatin. The identification of enteric neural targets of scrapie prions early in disease progression contributes significantly in understanding the factors involved in peripheral neuroinvasion and neural dissemination of prions.

\section{Materials and methods}

\section{Oral inoculation model}

All animal experiments were approved by the Washington State University Institutional Animal Care and Use Committee. The study included seven Montadale or MontadaleXSuffolk lambs born to Montadale ewes. All lambs were VRQ/VRQ (see "Genotyping" section below), and on the day of birth were fed half a cotyledon from a placenta shed previously from an unrelated ARQ/VRQ ewe clinically affected with scrapie and with staining for $\mathrm{PrP}^{\mathrm{Sc}}$ in sections of medulla at the level of the obex. Cotyledons were stored at $-20^{\circ} \mathrm{C}$ until used.

Peripheral prion replication in lambs was assessed antemortem by third eyelid [31] or rectal [13, 18] biopsy obtained at 4-6 months of age. Lambs were humanely euthanized at about 7 months of age by intravenous injection of sodium pentobarbital (Fatal-Plus; Vortech Pharmaceuticals, Dearborn, MI). Tissues collected immediately postmortem included medulla, thoracolumbar spinal cord, celiacomesenteric ganglia, ileocecal lymph node, ileocecal junction, and a $30 \mathrm{~cm}$ length of ileum ending within $\sim 3 \mathrm{~cm}$ of the ileocecal junction. All tissues were fixed by immersion in $10 \%$ neutral-buffered formalin; the ileum was also gently distended with formalin.

\section{Genotyping}

Approximately $100 \mathrm{ng}$ DNA was used as a template for amplification of the open reading frame of PRNP using the following primer pair: 5'-GGCATTTGATGCTGACACC-3' and 5'-TACAGGGCTGCAGGTAGAC-3', corresponding to nucleotide positions $22234-22252$ and $23106-23125$ of GenBank accession no. U67922. Reactions were performed in a final volume of $90 \mu \mathrm{L}$ under the following conditions: $1 \times$ Qiagen PCR buffer, $2.5 \mathrm{mM} \mathrm{MgCl} 2$ and $2.5 \mathrm{U}$ Taq polymerase (201225, TaqPCR Core kit; Qiagen, Valencia, CA). Amplification was performed under a temperature regime of $95^{\circ} \mathrm{C}$ for $5 \mathrm{~min}, 62^{\circ} \mathrm{C}$ for $30 \mathrm{~s}$, and $72^{\circ} \mathrm{C}$ for $59 \mathrm{~s}$ for one cycle; $95^{\circ} \mathrm{C}$ for $30 \mathrm{~s}, 62^{\circ} \mathrm{C}$ for $30 \mathrm{~s}$, and $72^{\circ} \mathrm{C}$ for $59 \mathrm{~s}$ for 30 cycles; and $95^{\circ} \mathrm{C}$ for $30 \mathrm{~s}, 62^{\circ} \mathrm{C}$ for $30 \mathrm{~s}$ and $72^{\circ} \mathrm{C}$ for 7 min for one cycle. Amplified products were 
sequenced by standard dideoxynucleotide analysis (Amplicon Express, Pullman, WA) using primer pair 5'-CTGGGGTC AAGGTGGTAGCC-3' and 5'-GGTGGTGACTGTGTGTT GCTTGA-3', corresponding to nucleotide positions 22553-22573 and 22838-22860 of GenBank accession no. U67922. Genotypes are reported as the deduced amino acid sequences at codons 136 (alanine, A; valine, V), 154 (arginine, R; histidine, H), and 171 (glutamine, Q; arginine, R) of the diploid genotype.

$\operatorname{PrP}^{\mathrm{Sc}}$ detection by ELISA

A commercial test developed for lymphoid tissue (HerdChek Chronic Wasting Disease [CWD] Antigen Test kit; IDEXX, Westbrook, Maine) was used for detection of $\mathrm{PrP}^{\mathrm{Sc}}$ in unfixed cotyledons as previously described [2]. This test is used for the postmortem detection of $\operatorname{PrP}^{\mathrm{Sc}}$ in white-tailed deer retropharyngeal lymph node tissue but is also suitable for the detection of $\operatorname{PrP}^{\mathrm{Sc}}$ in sheep cotyledons; the kit utilizes a $\operatorname{PrP}^{\mathrm{Sc}}$ ligand immobilized on the surface of the CWD-antigen capture plate and monoclonal antibodies that recognize the ovine PrP protein. Briefly, $300 \mathrm{mg}$ of cotyledon was homogenized twice in a FastPrep instrument (Qbiogene, Carlsbad, CA) for $30 \mathrm{~s}$ each at maximum speed $(6.5 \mathrm{~m} / \mathrm{s})$ in a disruption tube containing ceramic beads and $0.9 \mathrm{~mL}$ of distilled, deionized water. The ELISA was then conducted according to the manufacturer's protocols. Interpretation of samples analyzed by ELISA was performed by comparing the $A_{450}$ of the cotyledon samples with that of negative- and positive-control samples supplied with the kit (reference wavelength $=620 \mathrm{~nm}$ ). Samples were considered positive if the mean $A_{450}$ values were greater than or equal to the cutoff value as calculated by the test manufacturer.
Immunohistochemistry (IHC)

All formalin-fixed tissues were placed in cassettes, incubated for $60 \mathrm{~min}$ in $98 \%$ formic acid, washed extensively in distilled water, and re-equilibrated in formalin for $24 \mathrm{~h}$, prior to paraffin embedding. Thin $(3-5 \mu \mathrm{m})$ paraffin sections were mounted on Superfrost Plus slides, air dried overnight, and then baked at $57^{\circ} \mathrm{C}$ for $100 \mathrm{~min}$. IHC staining was carried out using a BenchMark automated processor (Ventana Medical Systems, Tucson, AZ) with modifications to the technique previously described [31, 43]. Antigen retrieval was achieved by $60-90$ min heated incubation in CC1 buffer (Ventana Medical Systems). Scrapie-associated prion protein $\left(\mathrm{PrP}^{\mathrm{Sc}}\right)$ was detected using a cocktail of well-characterized monoclonal antibodies (F89/160.1.5 and F99/97.6.1; Table 1) applied for $32 \mathrm{~min}$ at $37^{\circ} \mathrm{C}$. Evaluation of $\operatorname{PrP}^{\mathrm{Sc}}$ dissemination was determined using Basic AEC Detection Kit (760-020; Ventana Medical Systems). Slides were then counterstained using Bluing Reagent and Hematoxylin kits (Ventana Medical Systems) and coverslipped in aqueous mounting media (S3025; Dako, Carpinteria, CA). In dual fluorescence labeling studies, an antibody directed toward a neurochemical of interest (Table 1) was included in the cocktail of anti-PrP $\mathrm{P}^{\mathrm{Sc}}$ primary antibodies. Relevant combinations of fluorescently-labeled secondary antibodies were applied for $20 \mathrm{~min}$ at $37^{\circ} \mathrm{C}$ (Table 2). Fluorescently labeled slides were coverslipped using Prolong Gold antifade reagent (P36930; Molecular Probes, Eugene, OR).

Using these techniques, $\mathrm{PrP}^{\mathrm{Sc}}$ staining could be detected in the obex, lymph nodes, and ileum from a clinically affected ewe but not from an unexposed, clinically normal ewe. IHC staining for all neural and glial marker antibodies was dependent upon inclusion of the primary antibody and an appropriate fluorophore-conjugated secondary antibody.

Table 1 Primary antibodies

\begin{tabular}{|c|c|c|c|c|}
\hline Target & Name & $\begin{array}{l}\text { Species and } \\
\text { isotype }\end{array}$ & $\begin{array}{l}\text { Working dilution/ } \\
\text { concentration }\end{array}$ & Source (reference) \\
\hline \multirow[t]{2}{*}{$\mathrm{PrP}^{\mathrm{Sc}}$} & F89/160.1.5 & Mouse $\operatorname{IgG}_{1}$ & $5 \mu \mathrm{g} / \mathrm{mL}$ & $\begin{array}{l}\text { Dr. Katherine O'Rourke, USDA-ARS, } \\
\text { Pullman, WA }[30,31]\end{array}$ \\
\hline & F99/97.6.1 & Mouse $\mathrm{IgG}_{1}$ & $5 \mu \mathrm{g} / \mathrm{mL}$ & $\begin{array}{l}\text { Dr. Katherine O'Rourke, USDA-ARS, } \\
\text { Pullman, WA [31] }\end{array}$ \\
\hline Glial fibrillary acid protein & GFAP & Rabbit IgG & $1: 400$ & Z0334; Dako, Carpinteria, CA [24, 45] \\
\hline $\begin{array}{l}\text { Elav protein (human neuronal } \\
\text { protein, } \mathrm{Hu} \text { ) }\end{array}$ & $\mathrm{Hu}$ & Mouse $\mathrm{IgG}_{2 \mathrm{~b}}$ & $1: 200$ & A-21271; Molecular Probes, Eugene, OR [8] \\
\hline Neural nitric oxide synthase & NOS & Rabbit IgG & $1: 200$ & $\begin{array}{l}\text { SA227; Biomol Research Laboratories, } \\
\text { Plymouth Meeting, PA [29] }\end{array}$ \\
\hline Protein gene product 9.5 & PGP & Rabbit IgG & $1: 200$ & Z5116; Dako \\
\hline Somatostatin & SOM & Rabbit IgG & $1: 1,600$ & 20067; ImmunoStar \\
\hline Substance P & SP & Rat $\operatorname{IgG}_{2 \mathrm{a}}$ & $1: 50$ & MAB356; Chemicon, Temecula, CA \\
\hline Vasoactive intestinal polypeptide & VIP & Guinea pig IgG & $1: 800$ & T-5030 (GHC7161); Peninsula Laboratories [32] \\
\hline
\end{tabular}


Table 2 Secondary antibodies used in fluorescence IHC

\begin{tabular}{lll}
\hline Target visualized & Antibody & Source \\
\hline PrP $^{\mathrm{Sc}}, \mathrm{Hu}$ & Cy3 AffiniPure donkey anti-mouse IgG & $\begin{array}{c}\text { 715-165-150; Jackson ImmunoResearch Laboratories, } \\
\text { West Grove, PA }\end{array}$ \\
$\mathrm{SP}$ & Cy3 AffiniPure donkey anti-rat IgG & $712-165-150 ;$ Jackson ImmunoResearch Laboratories \\
$\mathrm{PrP}$ & Alexa Fluor 488 goat anti-mouse IgG & A-11029; Molecular Probes, Eugene, OR \\
GFAP, NOS, PGP, SOM & Alexa Fluor 488 goat anti-rabbit IgG & A-11034; Molecular Probes, Eugene, OR \\
VIP & Alexa Fluor 488 goat anti-guinea pig IgG & A-11073; Molecular Probes, Eugene, OR \\
\hline
\end{tabular}

\section{Microscopy}

Slides were viewed and photographed using an Axio Imager.M1 microscope (Carl Zeiss Microimaging, Thornwood, NY) equipped with an LED illuminator for bright field microscopy and an X-Cite 120 Fl Illuminating system (EXFO Photonic Solutions, Mississauga, Ontario, Canada) for epi-fluorescence microscopy. Cy3 and Alexa Fluor 555 fluorescence were observed using the Carl Zeiss filter set 00 (excites 530-585 nm, dichroic mirror 600, $615 \mathrm{~nm}$ longpass filter), and Alexa Fluor 488 fluorescence was observed using the Carl Zeiss filter set 38HE (excites 450-490 nm, dichroic mirror 495, 500-550 nm band-pass filter). The microscope was equipped with an AxioCam MRc5 digital camera (Carl Zeiss Microimaging) connected to a computer workstation running AxioVision 4.5 imaging software (Carl Zeiss Microimaging). For presentation in Figs. 4 and 7, maximum intensity projections were produced from sequentially scanned $\mathrm{Z}$-stack series $(0.5-1 \mu \mathrm{m}$ intervals) using an LSM 510 META laser scanning microscope (Carl Ziess Microimaging) equipped with 488 and $543 \mathrm{~nm}$ lasers (pinholes set to 1 Airy unit).

\section{Statistical methods}

All analyses were performed using SAS for Windows (ver. 9.1.3, service pack 4; SAS Institute, Cary, NC). The data set was categorized by animal, enteric plexus location (myenteric or submucosal) and by neurochemical type (PGP, nNOS, SOM, SP, or VIP; abbreviations defined in Table 1). The total number of neurons (defined by somata staining) and the number of those colocalized with $\mathrm{PrP}^{\mathrm{Sc}}$ were recorded for each neurochemical type. The total association of $\mathrm{PrP}^{\mathrm{Sc}}$ colocalization in neurochemically-defined $\left(\mathrm{NOS}^{+}\right.$, $\mathrm{SOM}^{+}, \mathrm{SP}^{+}$, or $\mathrm{VIP}^{+}$) somata compared to colocalization in the total neural population $\left(\mathrm{PGP}^{+}\right)$was determined for each animal by Fisher's exact testing. The null hypothesis of random detection of $\mathrm{PrP}^{\mathrm{Sc}}$ amongst neurochemically-defined enteric neurons was assessed by conditional logistic regression using a generalized linear mixed model, the GLIMMIX procedure (rel. June 2006; SAS Institute), and the fixed effects of plexus location, neurochemical type, and the interaction of these two effects. The regression was conditioned by including the random effect of subjects (lambs) and adjusted for overdispersion by including the random effect of residuals. Holm-adjusted $P$ values $\left(P_{\text {adj }}\right)$ were produced using the method of Bonferroni in logical step-down fashion [23]. Odds ratios (ORs) and corresponding upper and lower $\mathrm{CL}_{\mathrm{adj}} \mathrm{S}$ are the exponentiation of the least squares means parameter and $\mathrm{CL}_{\mathrm{adj}} \mathrm{s}$ estimates, respectively. Least squares means parameter and Holm-adjusted 95\% confidence limit $\left(\mathrm{CL}_{\mathrm{adj}}\right)$ estimates were produced for two "families" of posthoc comparisons of interest; family-wise error rate, $\alpha=0.05$.

\section{Results}

Alimentary transmission and staging disease progression

Cotyledons randomly selected from the pool of cotyledons used for alimentary inoculation had $\mathrm{PrP}^{\mathrm{Sc}}$ staining by $\mathrm{IHC}$ and a $\operatorname{PrP}^{\mathrm{Sc}}$ ELISA titer between 1:64 and 1:256. Ewes giving birth to the lambs were not a likely source of $\mathrm{PrP}^{\mathrm{Sc}}$ since $\mathrm{PrP}^{\mathrm{Sc}}$ staining was neither detected by IHC in antemortem peripheral lymphoid tissues (third eyelid and rectal mucosa) and postmortem obex, nor by IHC and western blot in shed cotyledons randomly sampled at the birth of these lambs.

Tissues from a lamb euthanized before 2 weeks of age due to an unrelated illness were not collected. In the remaining six lambs, $\mathrm{PrP}^{\mathrm{Sc}}$ was detected antemortem in rectal mucosa-associated lymphoid tissue between 124-219 days of age, and in ileal Peyer's patches and ileocecal lymph node collected postmortem between 138-226 days of age (Fig. 1b, d, f; scrapienegative control tissues shown in Fig. 1a, c, e). $\mathrm{PrP}^{\mathrm{Sc}}$ was not detected in the central nervous system (medulla and intermediolateral column of T8-L3 spinal cord segments) or celiacomesenteric ganglia (138-226 days of age), except in one lamb (226 days of age) in which sparse punctate staining in celiacomesenteric ganglia appeared to be located mostly in satellite cells (Fig. $2 \mathrm{a}-\mathrm{d}$ ). $\operatorname{PrP}^{\mathrm{Sc}}$ was detected in the enteric nervous system of the ileum in five lambs aged 208-226 days, but not in a lamb aged 138 days (examples shown in Fig. 3). The appearance of $\mathrm{PrP}^{\mathrm{Sc}}$ staining within enteric somata was generally punctate (Fig. 3d-f, Fig. 4a-c) but sometimes 
Fig. $1 \operatorname{PrP}^{\mathrm{Sc}}$ staining (red) was not observed in various lymphoid tissues from a scrapienegative control ewe (a, c, e) but was readily detected in lymphoid tissues from a lamb orally inoculated with scrapie prions at birth (b, d, f). Lymphoid tissues shown are from: $\mathbf{a}, \mathbf{b}$ rectal mucosa-associated lymphoid tissue (RMALT); $\mathbf{c}, \mathbf{d}$ ileal Peyer's patch; $\mathbf{e}, \mathbf{f}$ ileocecal lymph node. Bars $100 \mu \mathrm{m}$
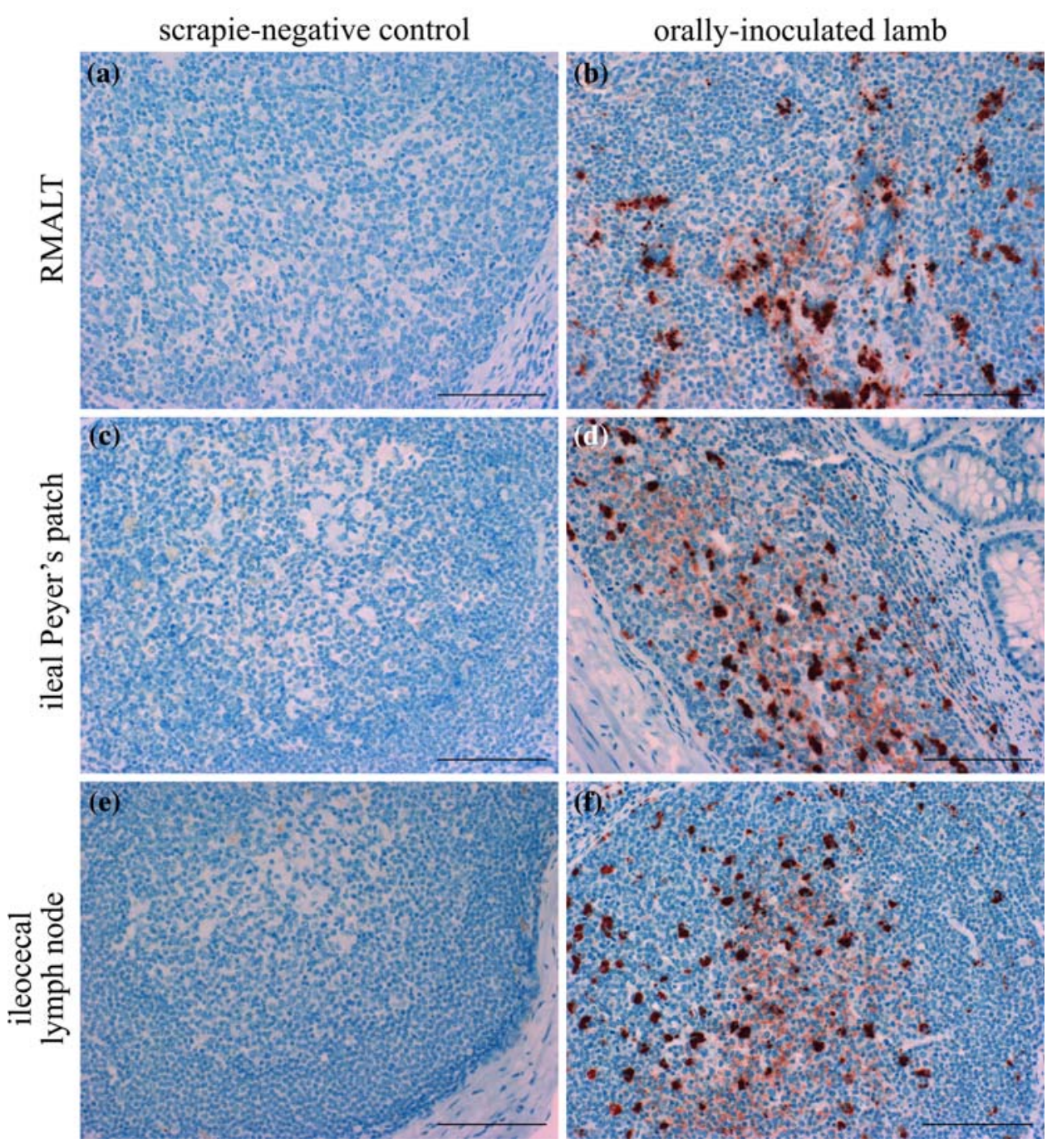

globular when near cell margins. $\mathrm{PrP}^{\mathrm{Sc}}$ was also occasionally observed within enteric glia (Fig. 4d-f).

Frequency of $\mathrm{PrP}^{\mathrm{Sc}}$ detection within defined populations of enteric neurons

The occurrence of $\mathrm{PrP}^{\mathrm{Sc}}$ in $\mathrm{PGP}^{+}$somata was tallied for a total of 10,841 myenteric neurons and 19,495 submucosal neurons. The frequency of $\mathrm{PrP}^{\mathrm{Sc}}$ detection in $\mathrm{PGP}^{+}$somata ranged from 1.21 to $11.67 \%$ (mean and standard deviation: $4.48 \pm 4.26 \%$ ) in myenteric neurons, and from 1.01 to $5.68 \%(2.57 \pm 1.82 \%)$ in submucosal neurons $(n=5$ lambs). Frequencies of $\operatorname{PrP}^{\mathrm{Sc}}$ detection in enteric neurons defined by plexus location and neurochemical type are shown for each lamb in Fig. 5. The pattern of $\mathrm{PrP}^{\mathrm{Sc}}$ detection frequency amongst eight enteric neural subgroups relative to that in $\mathrm{PGP}^{+}$somata varied between lambs except for a consistently increased detection frequency in $\mathrm{SOM}^{+}$ neurons of the myenteric plexus (Breslow-Day test for homogeneity: Chi-square $=1.7067, P=0.7895$ ).
The significance and strength of the association of $\mathrm{PrP}^{\mathrm{Sc}}$ detection frequency with subpopulations of enteric neurons was measured by odds ratio estimates for somata defined by plexus location and neurochemical type and analyzed by conditional logistic regression. The odds of $\mathrm{PrP}^{\mathrm{Sc}}$ detection were significantly dependent upon plexus location $(F=4.66, P=0.0376)$, neurochemical type $(F=20.59$, $P<0.0001)$, and the interaction of these main effects ( $F=6.66, P=0.0004)$. The detailed post-hoc analyses of this finding are summarized below and in Fig. 6.

$\mathrm{PrP}^{\mathrm{Sc}}$ was detected more frequently in the myenteric plexus versus the submucosal plexus (Fig. 6a) for the general population of neurons (PGP; 1.72, 1.21-2.44) and for the subpopulation of $\mathrm{SOM}^{+}$neurons $(3.92,2.09-7.35)$. Relative to local $\mathrm{PGP}^{+}$neural populations, the frequency of $\mathrm{PrP}^{\mathrm{Sc}}$ detection was significantly increased for only $\mathrm{SOM}^{+}$ neurons in the myenteric plexus $(3.87,2.16-6.94$; Fig. 6b) and in the submucosal plexus (1.70, 1.02-2.82; Fig. 6c). Significantly lower frequencies of detection were associated with $\mathrm{SP}^{+}$neurons in the myenteric plexus $(0.21,0.05-0.87$; 
Fig. 2 Detection of $\mathrm{PrP}^{\mathrm{Sc}}$ staining (red) in the celiacomesenteric ganglia from a lamb aged 226 days following oral inoculation with scrapie prions at birth. a $\operatorname{PrP}^{\mathrm{Sc}}$ detected in a satellite cell. The box depicts the region shown at higher magnification in b. $\mathbf{c} \operatorname{PrP}^{\mathrm{Sc}}$ at the margin of this ganglion cell may also be located in a satellite cell in which only a part of the nucleus is present in this section. The box depicts the region shown at higher magnification in d. Bars $50 \mu \mathrm{m}$ $(\mathbf{a}, \mathbf{c}), 5 \mu \mathrm{m}(\mathbf{b}, \mathbf{d})$
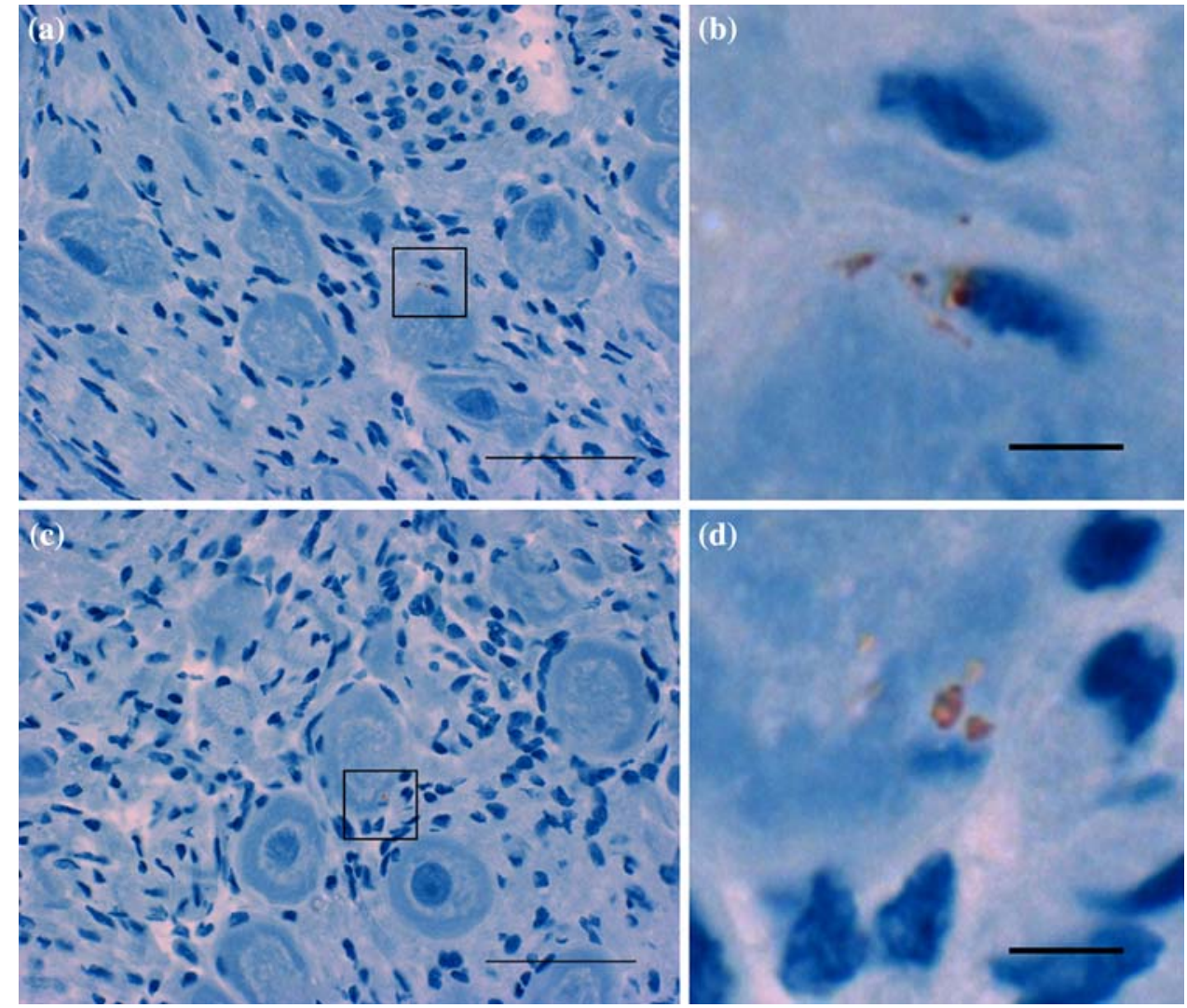
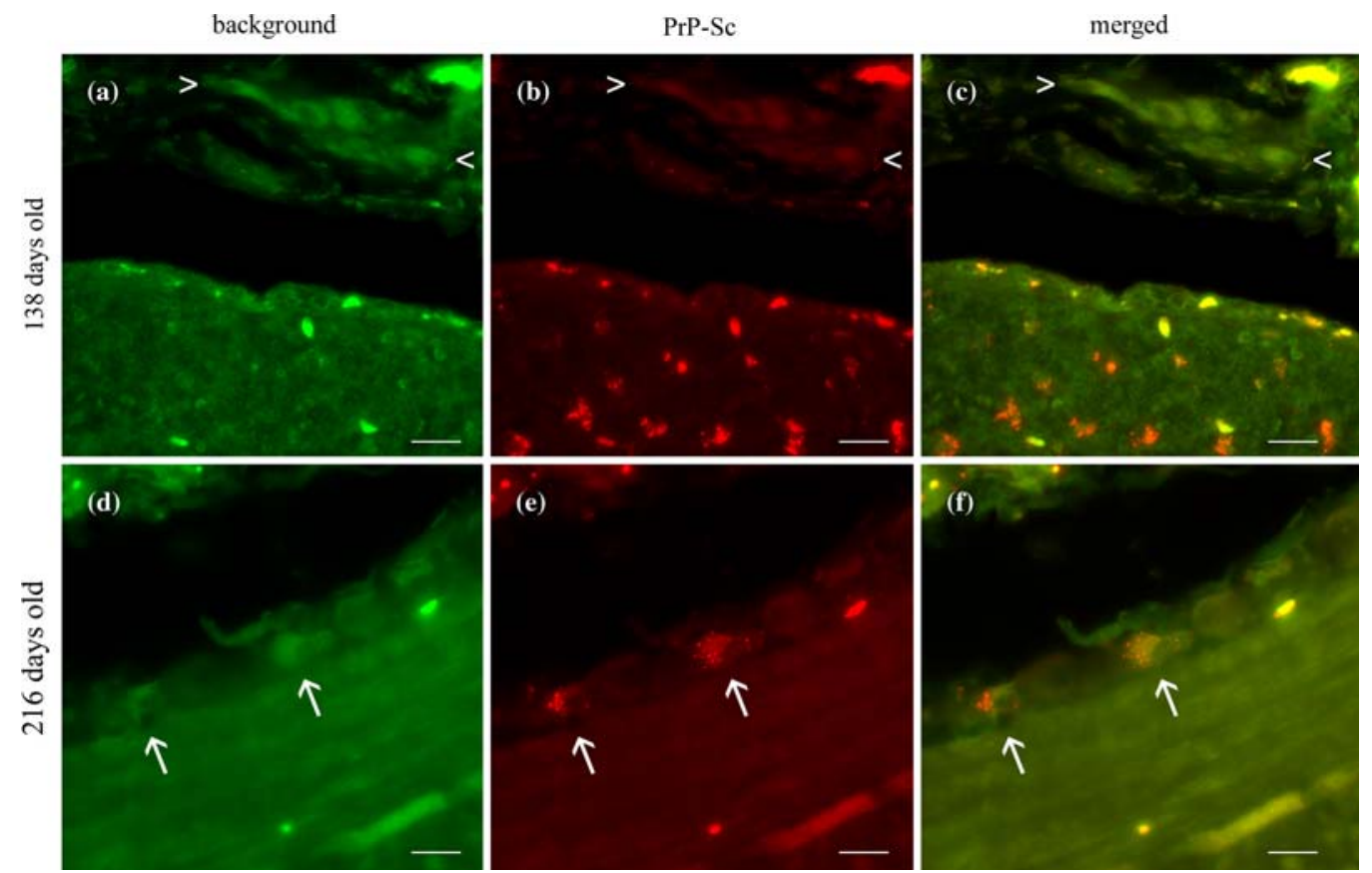

Fig. 3 Examples of $\operatorname{PrP}^{\mathrm{Sc}}$ staining (red) detected in the ileum of two lambs orally inoculated with scrapie prions at birth. a-c In a lamb aged 138 days, $\mathrm{PrP}^{\mathrm{Sc}}$ staining is present within a Peyer's patch follicle (lower half of image) but not within adjacent submucosal neurons (arrowheads denote ganglion limits). d-f $\mathrm{PrP}^{\mathrm{Sc}}$ staining in two submucosal neurons (arrows) of a lamb aged 216 days. $\mathrm{PrP}^{\mathrm{Sc}}$ staining was also

present in a Peyer's patch follicle located out of frame above this ganglion. The background (green) column is included to provide tissue contrast. $\operatorname{PrP}^{\mathrm{Sc}}$ staining remains red in the merged column of this single labeling experiment, whereas autofluorescence appears bright yellow. Images are maximum intensity projections from $6 \mu \mathrm{m}$ z-stacks. Bars $20 \mu \mathrm{m}$ 

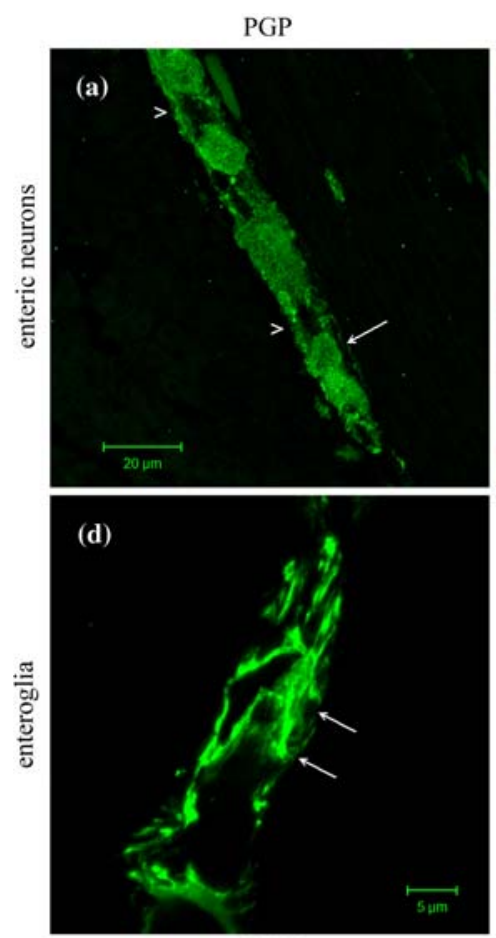

GFAP
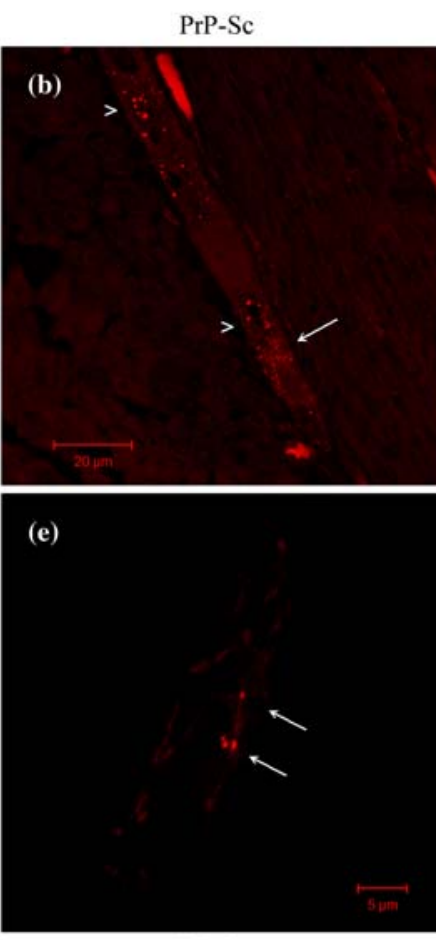

PrP-Sc
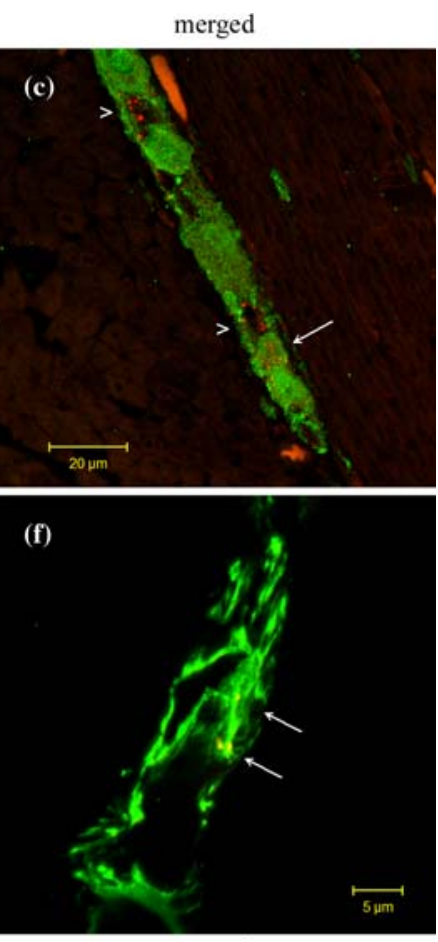

merged
Fig. 4 Initial detection of $\operatorname{PrP}^{\mathrm{Sc}}$ staining (red) in the enteric nervous system of the ileum from a lamb aged 216 days following oral inoculation with scrapie prions at birth. a-c $\operatorname{PrP}^{\mathrm{Sc}}$ detected within (arrow), and outside of (arrowheads), $\mathrm{PGP}^{+}$enteric neurons (green). d-f $\mathrm{PrP}^{\mathrm{Sc}}$

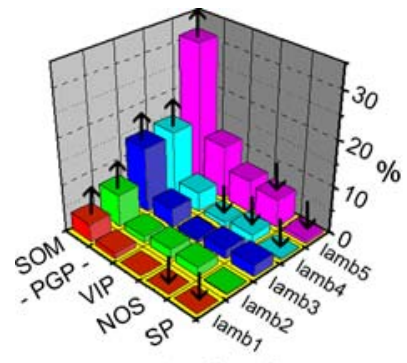

myenteric plexus

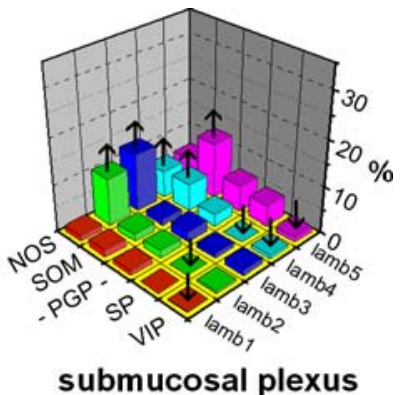

submucosal plexus
Fig. 5 Frequency of detecting $\operatorname{Pr}^{\mathrm{Sc}}$ staining within subpopulations of enteric neuron in the ileum of lambs early in disease progression following oral inoculation with scrapie prions at birth. Note the consistent increase in the frequency of $\operatorname{PrP}^{\mathrm{Sc}}$ detection within myenteric plexus $S_{S M}^{+}$neurons as compared to that in the general myenteric neuron population (-PGP-). Each bar color represents data from a lamb (lambs $1-5)$ at approximately 7 months of age. Frequency of $\operatorname{PrP}^{\mathrm{Sc}}$ detection is given as the percent $(\%$,vertical axis) within each type of neuron per lamb. Abbreviations are defined in Table 1. Arrows indicate the direction of significant differences (Fischer's exact test; $P<0.05$ )

Fig. 6b) and $\mathrm{VIP}^{+}$neurons in the submucosal plexus $(0.23$, 0.07-0.76; Fig. 6c).

$\mathrm{SOM}^{+}$nerve fibers in the ileum

$\mathrm{SOM}^{+}$nerve fibers were frequently observed projecting between mucosal epithelium and Peyer's patches with detected within (arrows) $\mathrm{GFAP}^{+}$enteric glia (green). Images are maximum intensity projections from $2.5 \mu \mathrm{m}(\mathbf{a}-\mathbf{c})$ and $1.5 \mu \mathrm{m}(\mathbf{d}-\mathbf{f})$ confocal z-stacks. Abbreviations defined in Table 1

$\operatorname{PrP}^{\mathrm{Sc}}$ staining (Fig. 7). Similar to a previous description [49], staining for SOM was also occasionally observed in "open-type" epithelial cells of the ileal mucosa (not shown).

\section{Discussion}

The process of neuroinvasion of the enteric nervous system by prions was studied in the ileum of sheep, the first peripheral region in which neuroinvasion occurs in naturally acquired disease $[3,12,47]$. We determined that the relative frequency of $\mathrm{PrP}^{\mathrm{Sc}}$ staining, used as a surrogate marker [1, 26] for scrapie prions within enteric neurons, is dependent upon that neuron's plexus location and neurochemical type. In particular, $\mathrm{SOM}^{+}$myenteric neurons were identified as a consistent target for neuroinvasion early in disease progression. From the evidence, we postulate that a significant subgroup of $\mathrm{SOM}^{+}$neurons innervate compartments of Peyer's patches where efficient neuroinvasion is thought to occur, and represent an efficient pathway for neural dissemination within the small intestine. We expect that prion invasion of neurons that do not convert $\mathrm{PrP}^{\mathrm{c}}$ into $\mathrm{PrP}^{\mathrm{Sc}}$ that is readily detectable by immunohistochemistry [4], should they exist within the enteric nervous system, would be underrepresented in the present study. 

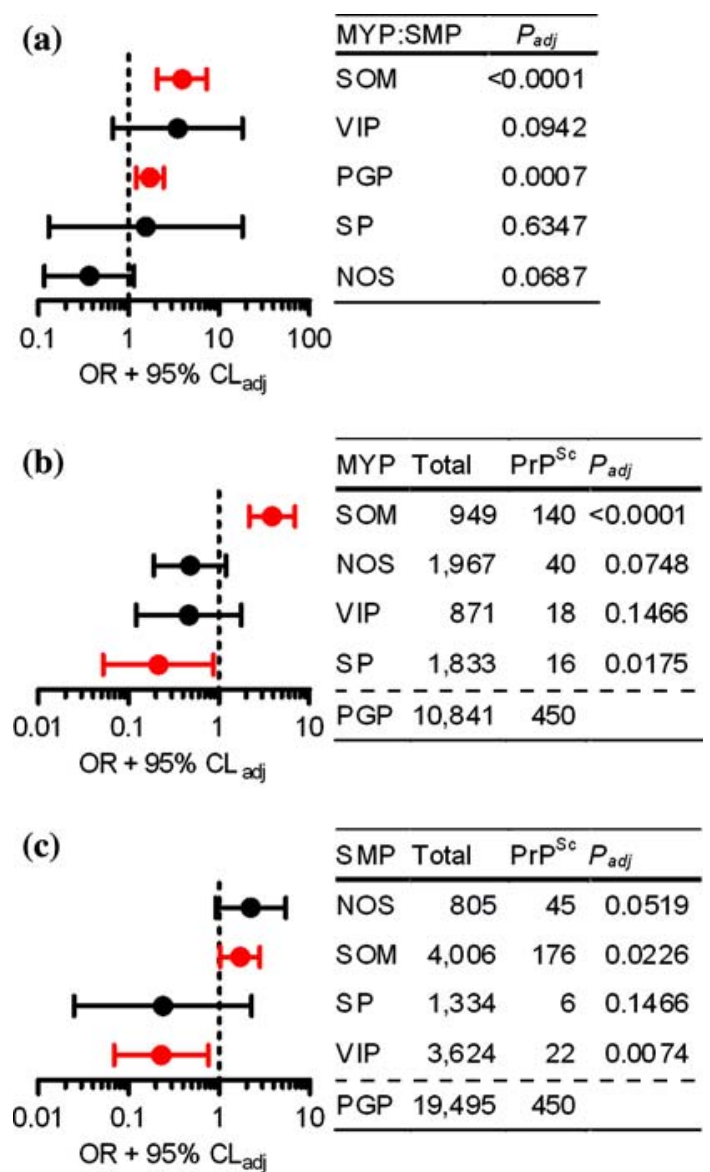

Fig. 6 The relative frequency of detecting $\mathrm{PrP}^{\mathrm{Sc}}$ staining within ileal enteric neurons of lambs is interdependent on plexus location and neurochemical type early in disease progression. a The frequency of $\mathrm{PrP}^{\mathrm{Sc}}$ detection was greater in the myenteric versus submucosal plexus for the general $(P G P)$ neural population and for the subpopulation of $S M^{+}$neurons. b, c SOM ${ }^{+}$neurons were the only subpopulation studied that had an increased frequency of $\mathrm{PrP}^{\mathrm{Sc}}$ detection in either plexus (b myenteric, c submucosal), relative to that in the respective general neural population. The difference between an odds ratio (OR) and 1 (dotted vertical lines) indicates the relative strength of the association with the frequency of $\mathrm{PrP}^{\mathrm{Sc}}$ detection. ORs significantly greater or less than 1 (depicted in red; $P_{\text {adj }}<0.05$ ) indicate associations with increased or decreased frequency, respectively, of $\operatorname{PrP}^{\mathrm{Sc}}$ detection. $C L_{a d j}$ Holm-adjusted confidence limits, $P_{a d j}$ Holm-adjusted $P$ values, $\operatorname{Pr} P^{S c}$ the number of neurons in which $\operatorname{PrP}^{\mathrm{Sc}}$ was detected, $M Y P$ myenteric plexus, SMP submucosal plexus, Total the total number of neurons counted. See Table 1 for abbreviations of neurochemical types. $y$-axis First column, $x$-axis $\log _{10}$

$\mathrm{SOM}^{+}$enteric neurons are targets of peripheral neuroinvasion by scrapie prions

There is consensus that transport of prions across gut epithelium and exposure of mucosal nerve fibers are processes relevant to peripheral neuroinvasion and neural dissemination $[5,26,28,36,47]$. Considering that the greatest proportion of mucosa-projecting neurons typically occurs in the submucosal plexus of large mammalian species [44], it is surprising that $\mathrm{PrP}^{\mathrm{Sc}}$ detection early in disease was most frequent in neurons located in the myenteric plexus (Fig. 6a, PGP), and was relatively infrequent in a major type of submucosal neuron (Fig. 6c, VIP). Further, $\operatorname{PrP}^{\mathrm{Sc}}$ detection in $\mathrm{SOM}^{+}$neurons of the myenteric plexus was very consistent and occurred at nearly $4 \times$ greater frequency (Fig. 6b).

$\mathrm{SOM}^{+}$enteric neurons of the small intestine generally belong to one of two classes that differ in function and projection: secretomotor neurons that project to the mucosal layer, and descending interneurons that synapse with other enteric neurons [6]. Determining the projections of $\mathrm{SOM}^{+}$ enteric nerve fibers in sheep is thus particularly germane to locating a compartment in which efficient neuroinvasion occurs. Given the present data, it is conceivable that $\mathrm{SOM}^{+}$ neurons targeted by scrapie prions are distributed in greatest proportion within myenteric ganglia but which, nevertheless, project to mucosal compartments in which efficient neuroinvasion occurs early in disease progression.

\section{Implications of $\mathrm{SOM}^{+}$secretomotor neurons targeted} by prions

Jeffrey et al. [25] observed, soon after the injection of infectious material into the lumen of the small intestine of lambs, that $\mathrm{PrP}^{\mathrm{Sc}}$ staining was widespread within mucosal villi. Mucosal villi are highly innervated by enteric neurons, including fibers of secretomotor neurons, which travel close to the epithelium to affect its function [21, 22, 41]. Fibers of numerous mucosa-projecting neurons, especially secretomotor neurons, are thus potentially exposed upon mucosal transportation of prion and prior to replication of prion within Peyer's patches.

In sheep, mucosal nerve fibers include those that express VIP, SP, NOS [8, 27, 51], and also SOM (Fig. 7). Furthermore, the secretomotor action of VIP, SP, and SOM is typically preserved within large mammalian species [44]. Therefore, it is not surprising that $\mathrm{PrP}^{\mathrm{Sc}}$ was detected in each of these neurochemical types of submucosal neuron early in disease progression following alimentary transmission in sheep. That $\operatorname{PrP}^{\mathrm{Sc}}$ was detected as much as $4 \times$ more frequently in $\mathrm{SOM}^{+}$neurons, however, may indicate that efficient enteric neuroinvasion occurs in a mucosal compartment uniquely innervated by $\mathrm{SOM}^{+}$neurons. Evidence implicates such a compartment is associated with Peyer's patches.

Neuroinvasion occurring via nerve fiber projections to Peyer's patches is consistent with the typical detection of $\mathrm{PrP}^{\mathrm{Sc}}$ first within Peyer's patches and then nearby ganglia, and with close associations between fibers and $\mathrm{PrP}^{\mathrm{Sc}}$-laden cells $[3,20]$. Recent evidence in mice further demonstrates that efficient neuroinvasion following alimentary transmission is dependent upon follicular dendritic cells [17], a cell type 

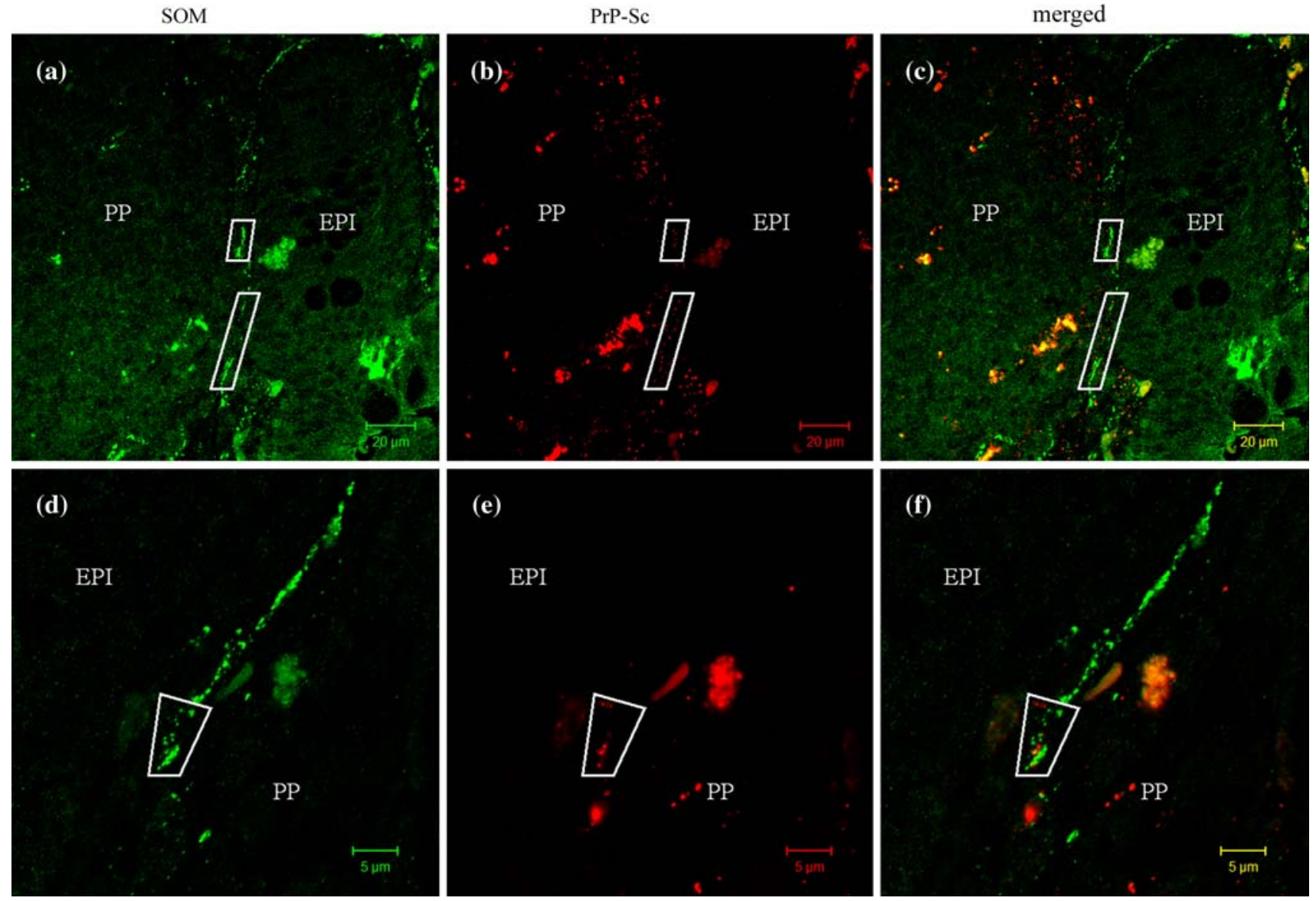

Fig. 7 Nerve fibers stained for SOM in the mucosal layer of the ileum from a lamb aged 208 days and orally inoculated with scrapie prions at birth. a-c, d-f Two examples of $\mathrm{SOM}^{+}$( green) nerve fibers projecting between the mucosal epithelium $(E P I)$ and a Peyer's patch $(P P)$ with

associated with nerve fibers in the interfollicular zone and dome of Peyer's patches [11]. Although SOM ${ }^{+}$Peyer's patch fibers are yet to be confirmed in mice [10,48], these have been observed in cats [14], and now also in sheep (Fig. 7). It is thus conceivable that in sheep, efficient neuroinvasion near Peyer's patches is dependent upon proximity of $\mathrm{SOM}^{+}$nerve fibers to $\mathrm{PrP}^{\mathrm{Sc}}$-laden immune cells or exosomes [35, 37].

Implications of $\mathrm{SOM}^{+}$descending interneurons targeted by prions

A subgroup of descending myenteric interneurons of the small intestine expresses SOM [6]. In the present study in sheep, prion targeting of $\mathrm{SOM}^{+}$descending interneurons would imply neuroinvasion early in disease occurred within ganglia, in contrast to that occurring outside of ganglia via nerve fibers. Nerve endings of extrinsic nerves are unlikely to have been a significant source of prion within enteric ganglia since $\operatorname{PrP}^{\mathrm{Sc}}$ was first detected in enteric neurons. Prions might alternatively enter ganglia from a non-neural
$\mathrm{PrP}^{\mathrm{Sc}}$-staining $($ red $)$. Note the relatively close association of $\mathrm{SOM}^{+}$ fibers with $\mathrm{PrP}^{\mathrm{Sc}}$ staining (boxes). Images are maximum intensity projections from $6 \mu \mathrm{m}(\mathbf{a}-\mathbf{c})$ and $2 \mu \mathrm{m}(\mathbf{d}-\mathbf{f})$ confocal z-stacks. SOM somatostatin

source, such as blood. However, if blood-borne prion were relevant to enteric neuroinvasion early in disease, then it would be reasonable to expect relatively higher frequency $\mathrm{PrP}^{\mathrm{Sc}}$ detection in vasomotor neurons.

Vasomotor neurons have not been extensively studied in large mammalian species but probably include subgroups of $\mathrm{VIP}^{+}$and $\mathrm{SP}^{+}$neurons $[44,51]$. The relative frequency of $\mathrm{PrP}^{\mathrm{Sc}}$ detection in $\mathrm{VIP}^{+}$and $\mathrm{SP}^{+}$neurons, however, was not increased in either plexus (Fig. 6b, c). Therefore, simple prion entry from a non-neural source such as blood does not likely account for the higher frequency of $\mathrm{PrP}^{\mathrm{Sc}}$ detection within $\mathrm{SOM}^{+}$neurons. Regardless, detection of $\mathrm{PrP}^{\mathrm{Sc}}$ in $\mathrm{SOM}^{+}$descending interneurons early in disease progression has implications for neural dissemination.

$\mathrm{SOM}^{+}$descending interneurons form a synaptic network that may descend the length of the small intestine-from duodenum to ileum, at least in guinea pigs [ $9,33,34,42]$. If this also occurs in sheep, then prion dissemination through $\mathrm{SOM}^{+}$descending interneurons might account for the observed oral spread of prion from the ileum to duodenum $[3,47]$. 
In summary, following neonatal alimentary transmission in sheep, immunohistochemical detection of $\mathrm{PrP}^{\mathrm{Sc}}$ (as a surrogate marker for neuroinvasion by scrapie prions) in ileal enteric neurons was interdependent on the neuron's plexus location and neurochemical type. Specifically, $\mathrm{SOM}^{+}$neurons, especially those located in the myenteric plexus, were found to be targets of neuroinvasion early in disease progression. These results are consistent with the hypothesis that efficient neuroinvasion occurs near Peyer's patches in compartments innervated by $\mathrm{SOM}^{+}$neurons. In addition, neuroinvasion of $\mathrm{SOM}^{+}$enteric neurons early in disease progression could explain the neural dissemination observed within the small intestine of sheep with naturally acquired disease.

Acknowledgments We thank Tom Truscott for histological assistance; Duane Chandler, Alicia Ewing, Jim Reynolds, Caitlin Rizzo, and Ira Mickelsen for assistance with animal care and necropsy; and Bruce Mackey (USDA, Albany, CA) for statistical consultation. This work was paid for by CRIS 5348-32000-019-00D from the Agricultural Research Service, US Department of Agriculture. Lindsay Fry was supported by a summer research stipend from the Research Scholars Program, College of Veterinary Medicine, Washington State University. Mention of trade names or commercial products in this article is solely for the purpose of providing specific information and does not imply recommendation or endorsement by the US Department of Agriculture.

\section{References}

1. Aguzzi A, Heikenwalder M, Miele G (2004) Progress and problems in the biology, diagnostics, and therapeutics of prion diseases. J Clin Invest 114:153-160

2. Alverson J, O'Rourke KI, Baszler TV (2006) PrPSc accumulation in fetal cotyledons of scrapie-resistant lambs is influenced by fetus location in the uterus. J Gen Virol 87:1035-1041

3. Andreoletti O, Berthon P, Marc D, Sarradin P, Grosclaude J, van Keulen L, Schelcher F, Elsen JM, Lantier F (2000) Early accumulation of $\operatorname{PrP}(\mathrm{Sc})$ in gut-associated lymphoid and nervous tissues of susceptible sheep from a Romanov flock with natural scrapie. J Gen Virol 81:3115-3126

4. Barron RM, Campbell SL, King D, Bellon A, Chapman KE, Williamson RA, Manson JC (2007) High titers of transmissible spongiform encephalopathy infectivity associated with extremely low levels of PrPSc in vivo. J Biol Chem 282:35878-35886

5. Beekes M, McBride PA (2007) The spread of prions through the body in naturally acquired transmissible spongiform encephalopathies. FEBS J 274:588-605

6. Brookes SJH, Costa M (2002) Cellular organization of the mammalian enteric nervous system. In: Brookes SJH, Costa M (eds) Innervation of the gastrointestinal tract. Taylor and Francis, New York, pp 393-468

7. Bueler H, Aguzzi A, Sailer A, Greiner RA, Autenried P, Aguet M, Weissmann C (1993) Mice devoid of PrP are resistant to scrapie. Cell 73:1339-1347

8. Chiocchetti R, Grandis A, Bombardi C, Lucchi ML, Dal Lago DT, Bortolami R, Furness JB (2006) Extrinsic and intrinsic sources of calcitonin gene-related peptide immunoreactivity in the lamb ileum: a morphometric and neurochemical investigation. Cell Tissue Res 323:183-196
9. Costa M, Furness JB, Smith IJ, Davies B, Oliver J (1980) An immunohistochemical study of the projections of somatostatin-containing neurons in the guinea-pig intestine. Neuroscience 5:841-852

10. De Jonge F, Van Nassauw L, De Man JG, De Winter BY, Van Meir F, Depoortere I, Peeters TL, Pelckmans PA, Van Marck E, Timmermans JP (2003) Effects of Schistosoma mansoni infection on somatostatin and somatostatin receptor $2 \mathrm{~A}$ expression in mouse ileum. Neurogastroenterol Motil 15:149-159

11. Defaweux V, Dorban G, Demonceau C, Piret J, Jolois O, Thellin O, Thielen C, Heinen E, Antoine N (2005) Interfaces between dendritic cells, other immune cells, and nerve fibres in mouse Peyer's patches: potential sites for neuroinvasion in prion diseases. Microsc Res Tech 66:1-9

12. Ersdal C, Ulvund MJ, Espenes A, Benestad SL, Sarradin P, Landsverk T (2005) Mapping PrPSc propagation in experimental and natural scrapie in sheep with different PrP genotypes. Vet Pathol 42:258-274

13. Espenes A, Press CM, Landsverk T, Tranulis MA, Aleksandersen M, Gunnes G, Benestad SL, Fuglestveit R, Ulvund MJ (2006) Detection of $\operatorname{PrP}(\mathrm{Sc})$ in rectal biopsy and necropsy samples from sheep with experimental scrapie. J Comp Pathol 134:115-125

14. Feher E, Fodor M, Burnstock G (1992) Distribution of somatostatin-immunoreactive nerve fibres in Peyer's patches. Gut 33:11951198

15. Furness JB (2006) Structure of the enteric nervous system. In: Furness JB (ed) The enteric nervous system. Blackwell, Malden, pp $1-28$

16. Gabella G (1987) The number of neurons in the small intestine of mice, guinea-pigs and sheep. Neuroscience 22:737-752

17. Glaysher BR, Mabbott NA (2007) Role of the GALT in scrapie agent neuroinvasion from the intestine. J Immunol 178:3757-3766

18. Gonzalez L, Jeffrey M, Siso S, Martin S, Bellworthy SJ, Stack MJ, Chaplin MJ, Davis L, Dagleish MP, Reid HW (2005) Diagnosis of preclinical scrapie in samples of rectal mucosa. Vet Rec 156:846847

19. Heggebo R, Press CM, Gunnes G, Lie KI, Tranulis MA, Ulvund M, Groschup MH, Landsverk T (2000) Distribution of prion protein in the ileal Peyer's patch of scrapie-free lambs and lambs naturally and experimentally exposed to the scrapie agent. J Gen Virol 81:2327-2337

20. Heggebo R, Gonzalez L, Press CM, Gunnes G, Espenes A, Jeffrey M (2003) Disease-associated PrP in the enteric nervous system of scrapie-affected Suffolk sheep. J Gen Virol 84:1327-1338

21. Hens J, Schrodl F, Brehmer A, Adriaensen D, Neuhuber W, Scheuermann DW, Schemann M, Timmermans JP (2000) Mucosal projections of enteric neurons in the porcine small intestine. J Comp Neurol 421:429-436

22. Hens J, Vanderwinden JM, De Laet MH, Scheuermann DW, Timmermans JP (2001) Morphological and neurochemical identification of enteric neurones with mucosal projections in the human small intestine. J Neurochem 76:464-471

23. Holm S (1979) A simple sequentially rejective multiple test procedure. Scand J Stat 6:65-70

24. Hortells P, Monzon M, Monleon E, Acin C, Vargas A, Bolea R, Lujan L, Badiola JJ (2006) Pathological findings in retina and visual pathways associated to natural Scrapie in sheep. Brain Res 1108:188-194

25. Jeffrey M, Gonzalez L, Espenes A, Press CM, Martin S, Chaplin M, Davis L, Landsverk T, MacAldowie C, Eaton S, McGovern G (2006) Transportation of prion protein across the intestinal mucosa of scrapie-susceptible and scrapie-resistant sheep. J Pathol 209:4-14

26. Jeffrey M, Gonzalez L (2007) Classical sheep transmissible spongiform encephalopathies: pathogenesis, pathological phenotypes and clinical disease. Neuropathol Appl Neurobiol 33:373-394

27. Lalatta-Costerbosa G, Mazzoni M, Clavenzani P, Di Guardo G, Mazzuoli G, Marruchella G, De Grossi L, Agrimi U, Chiocchetti 
R (2007) Nitric oxide synthase immunoreactivity and NADPH-d histochemistry in the enteric nervous system of Sarda breed sheep with different PrP genotypes in whole-mount and cryostat preparations. J Histochem Cytochem 55:387-401

28. Mabbott NA, MacPherson GG (2006) Prions and their lethal journey to the brain. Nat Rev Microbiol 4:201-211

29. Mbaku EM, Zhang L, Pearce WJ, Duckles SP, Buchholz J (2003) Chronic hypoxia alters the function of NOS nerves in cerebral arteries of near-term fetal and adult sheep. J Appl Physiol 94:724-732

30. O'Rourke KI, Baszler TV, Miller JM, Spraker TR, Sadler-Riggleman I, Knowles DP (1998) Monoclonal antibody F89/160.1.5 defines a conserved epitope on the ruminant prion protein. J Clin Microbiol 36:1750-1755

31. O'Rourke KI, Baszler TV, Besser TE, Miller JM, Cutlip RC, Wells GA, Ryder SJ, Parish SM, Hamir AN, Cockett NE, Jenny A, Knowles DP (2000) Preclinical diagnosis of scrapie by immunohistochemistry of third eyelid lymphoid tissue. J Clin Microbiol 38:3254-3259

32. Pfannkuche H, Schemann M, Gabel G (2002) Ruminal muscle of sheep is innervated by non-polarized pathways of cholinergic and nitrergic myenteric neurones. Cell Tissue Res 309:347-354

33. Pompolo S, Furness JB (1998) Quantitative analysis of inputs to somatostatin-immunoreactive descending interneurons in the myenteric plexus of the guinea-pig small intestine. Cell Tissue Res 294:219-226

34. Portbury AL, Pompolo S, Furness JB, Stebbing MJ, Kunze WA, Bornstein JC, Hughes S (1995) Cholinergic, somatostatin-immunoreactive interneurons in the guinea pig intestine: morphology, ultrastructure, connections and projections. J Anat 187:303-321

35. Porto-Carreiro I, Fevrier B, Paquet S, Vilette D, Raposo G (2005) Prions and exosomes: from PrPc trafficking to PrPsc propagation. Blood Cells Mol Dis 35:143-148

36. Press CM, Heggebo R, Espenes A (2004) Involvement of gutassociated lymphoid tissue of ruminants in the spread of transmissible spongiform encephalopathies. Adv Drug Deliv Rev 56:885-899

37. Prinz M, Heikenwalder M, Junt T, Schwarz P, Glatzel M, Heppner FL, Fu YX, Lipp M, Aguzzi A (2003) Positioning of follicular dendritic cells within the spleen controls prion neuroinvasion. Nature 425:957-962

38. Prusiner SB, Groth D, Serban A, Koehler R, Foster D, Torchia M, Burton D, Yang SL, DeArmond SJ (1993) Ablation of the prion protein $(\mathrm{PrP})$ gene in mice prevents scrapie and facilitates production of anti-PrP antibodies. Proc Natl Acad Sci USA 90:10608-10612
39. Prusiner SB (1998) Prions. Proc Natl Acad Sci USA 95:1336313383

40. Shmakov AN, McLennan NF, McBride P, Farquhar CF, Bode J, Rennison KA, Ghosh S (2000) Cellular prion protein is expressed in the human enteric nervous system. Nat Med 6:840-841

41. Song ZM, Brookes SJ, Steele PA, Costa M (1992) Projections and pathways of submucous neurons to the mucosa of the guinea-pig small intestine. Cell Tissue Res 269:87-98

42. Song ZM, Brookes SJ, Ramsay GA, Costa M (1997) Characterization of myenteric interneurons with somatostatin immunoreactivity in the guinea-pig small intestine. Neuroscience 80:907-923

43. Spraker TR, O'Rourke KI, Balachandran A, Zink RR, Cummings BA, Miller MW, Powers BE (2002) Validation of monoclonal antibody F99/97.6.1 for immunohistochemical staining of brain and tonsil in mule deer (Odocoileus hemionus) with chronic wasting disease. J Vet Diagn Invest 14:3-7

44. Timmermans JP, Hens J, Adriaensen D (2001) Outer submucous plexus: an intrinsic nerve network involved in both secretory and motility processes in the intestine of large mammals and humans. Anat Rec 262:71-78

45. Tolcos M, Harding R, Loeliger M, Breen S, Cock M, Duncan J, Rees S (2003) The fetal brainstem is relatively spared from injury following intrauterine hypoxemia. Brain Res Dev Brain Res 143:73-81

46. van Keulen LJ, Schreuder BE, Vromans ME, Langeveld JP, Smits MA (1999) Scrapie-associated prion protein in the gastrointestinal tract of sheep with natural scrapie. J Comp Pathol 121:55-63

47. van Keulen LJ, Vromans ME, van Zijderveld FG (2002) Early and late pathogenesis of natural scrapie infection in sheep. APMIS 110:23-32

48. Van Op den Bosch J, van Nassauw L, Lantermann K, van Marck E, Timmermans JP (2007) Effect of intestinal inflammation on the cell-specific expression of somatostatin receptor subtypes in the murine ileum. Neurogastroenterol Motil 19:596-606

49. Vergara-Esteras P, Harrison FA, Brown D (1990) The localization of somatostatin-like immunoreactivity in the alimentary tract of the sheep with observations on the effect of an infection with the parasite Haemonchus contortus. Exp Physiol 75:779-789

50. Vulchanova L, Casey MA, Crabb GW, Kennedy WR, Brown DR (2007) Anatomical evidence for enteric neuroimmune interactions in Peyer's patches. J Neuroimmunol 185:64-74

51. Wathuta EM (1986) The distribution of vasoactive intestinal polypeptide-like, substance P-like and bombesin-like immunoreactivity in the digestive system of the sheep. Q J Exp Physiol 71:615-631 